\title{
PRESENÇA DE LEISHMANIA SSP. EM NÓDULO DÉRMICO de um cão negativo aos testes parasitológicos de linfonodo e medula óssea
}

\author{
Presence of Leishmania spp. in a dermal nodule of a \\ dog negative at parasitological tests of lymph node and \\ bone marrow
}

\author{
Mayla de Lisbôa Padilha ${ }^{1 *} \mathbb{( \mathbb { D }}_{\text {, Lídio Ricardo Bezerra de Melo }}{ }^{\mathbb{1}}$, Neiliane Medeiros Dantas, \\ Mayara Candido da Silva Leite Cardoso ${ }^{1}$
}

*Autor Correspondente: Mayla de Lisbôa Padilha. Universidade Federal de Campina Grande (UFCG). Av. Universitária, s/n, Santa Cecília, Patos, PB, Brasil. CEP: 58708-110. E-mail: maylapadilha@hotmail.com

\begin{abstract}
Como citar: PADILHA, Mayla de Lisbôa et al. Presença de Leishmania ssp. em nódulo dérmico de um cão negativo aos testes parasitológicos de linfonodo e medula óssea. Revista de Educação Continuada em Medicina Veterinária e Zootecnia do CRMV-SP, São Paulo, v.19, n.3, 2021. e38030. Doi 10.36440/recmvz.v19i1.38030

Cite as: PADILHA, Mayla de Lisbôa et al. Presence of Leishmania spp. in a dermal nodule of a dog negative at parasitological tests of lymph node and bone marrow. Journal of Continuing Education in Veterinary Medicine and Animal Science of CRMV-SP, São Paulo, v.19, n.3, 2021. e38030. Doi 10.36440/recmvz.v19i1.38030
\end{abstract}

\section{Resumo}

A leishmaniose visceral canina, zoonose de grande importância para a saúde pública, é uma enfermidade crônica que resulta em sinais clínicos variados, dificultando seu diagnóstico. 0 diagnóstico definitivo da doença em cães baseia-se nos sinais clínicos associados à exames parasitológicos que, além de serem rápidos, possuem alta especificidade. Objetivou-se relatar a detecção de formas amastigotas de Leishmania spp. por meio de citologia de nódulos dérmicos de um cão com ausência de formas amastigotas, ao exame parasitológico, em amostras de medula óssea, linfonodos poplíteos e cervicais superficial direito e esquerdo. Uma cadela, poodle, de dez anos, com histórico de problemas dermatológicos e surgimento de nódulos dérmicos nas regiões dorsal e interdigital há cerca de dois anos foi avaliada. Ao exame físico observou-se alopecia discreta e difusa na região dorsal, com descamação. Era possível se observar nódulos com cerca de 3-5 cm de diâmetro, bem delimitados, sólidos e com aspecto inflamado nas regiões dorsal e interdigital; o animal também apresentava onicogrifose. Após avaliação clínica, realizou-se citologia de medula óssea, linfonodos poplíteos e cervicais superficiais, sendo estes negativos para a presença de formas de parasitas. Adicionalmente, amostras citológicas dos nódulos dérmicos foram colhidas tendo

1 Graduanda do curso de Medicina Veterinária, Universidade Federal de Campina Grande (UFCG), Patos, PB, Brasil

2 Aluno do Programa de Pós-Graduação em Ciência e Saúde Animal, Universidade Federal de Campina Grande (UFCG), Patos, PB, Brasil 
sido observadas formas amastigotas de Leishmania spp. nesses materiais. Conclui-se que a citologia do nódulo dérmico foi um método complementar de diagnóstico de leishmaniose em um cão negativo ao exame parasitológico de amostras de medula óssea e linfonodos.

Palavras-chave: Dermatite nodular. Saúde pública. Diagnóstico.

\section{Abstract}

Canine visceral leishmaniasis, a zoonosis of great public health importance, is a chronic disease that presents varied clinical signs, making its diagnosis very difficult. The definitive diagnosis of this disease is based on clinical signs associated with parasitological evaluations which, in addition to being quick, show high specificity. The objective of this study was to report the detection of amastigote forms of Leishmania spp. by cytology of dermal nodules from a dog negative at parasitological tests of bone marrow, popliteal and right superficial cervical and left lymph node samples. A female dog with a history of dermatological problems and the appearance of dermal nodules in the dorsal and interdigital regions was treated during the past two years. At physical examination, a slight diffuse alopecia was noted on the dorsal region, with desquamation. It was also possible to observe well defined nodules measuring about 3-5 cm of diameter, solid and with an inflammatory aspect on the dorsal and interdigital regions; the dog also presented onychogryphosis. After clinical evaluation, bone marrow, popliteal and superficial cervical lymph node aspiration biopsies were performed, and all of these were negative for the presence of parasites. Additionally, cytological samples of dermal nodules were collected where amastigote forms of Leishmania spp. were observed. We concluded that dermal nodule cytology was a complementary method for diagnosing visceral leishmaniasis in a dog negative at parasitological evaluation of bone marrow and lymph node samples.

Keywords: Nodular dermatitis. Public health. Diagnosis.

\section{Introdução}

A leishmaniose visceral canina (LVC), zoonose de grande importância para a saúde pública, é uma enfermidade crônica que apresenta sinais clínicos variados no cão, dificultando seu diagnóstico. Dentre as alterações sistêmicas estão destacadas a linfadenopatia generalizada, esplenomegalia, hepatomegalia, pneumonia intersticial, rinite, glomerulonefrite, dermatite esfoliativa, hipotricose, hiperqueratose nasodigital, onicogrifose e alopecia periocular (DIAS et al., 2011). As lesões dermatológicas são o sinal clínico mais comum e, muitas vezes, o único presente nesta enfermidade. As lesões dermatológicas são caracterizadas pela presença de pelos opacos, dermatite seca e esfoliativa, eritema com ulceração na orelha, focinho, alopecia periocular, hiperqueratose e piodermite secundária (SOLANO-GALLEGO et al., 2011).

O diagnóstico definitivo da doença baseia-se nos sinais clínicos associados à exames parasitológicos, que além de serem rápidos, possuem alta especificidade. A observação de formas do parasito pode ser realizada em aspirados de linfonodos, baço, medula óssea e, mais raramente, no sangue líquido sinovial e em líquidos cavitários, bem como em biopsia ou escarificação de pele (AZEVEDO et al., 2008). Outros testes auxiliam no diagnóstico desta zoonose como a imunohistoquímica, a reação em cadeia polimerase (PCR) e exames sorológicos (teste imunocromatográfico, ELISA, imunofluorescência indireta) (LAURENTI et al., 2014).

Objetivou-se relatar a detecção de formas amastigotas de Leishmania spp. por meio da citologia de biopsia aspirativa de nódulos dérmicos de um cão não positivo para a presença de formas do parasito ao teste parasitológico em amostras de medula óssea, linfonodos poplíteos e cervicais superficial direito e esquerdo. 


\section{Relato de caso}

Uma cadela, poodle, com dez anos de idade, castrada, pesando $4 \mathrm{~kg}$, que habita região endêmica para Leishmaniose com relato de caso de seres humanos, deu entrada em uma clínica particular com queixa de problemas dermatológicos, com surgimento de nódulos na região dorsal e interdigital, há cerca de dois anos. A tutora também relatou que o mesmo já havia passado por tratamentos anteriores para os problemas dermatológicos, sem sucesso. A mesma não soube informar os princípios ativos ou dose utilizados.

Ao exame físico, notou-se discreta alopecia difusa na região dorsal, com descamação. Era possível se observar nódulos com cerca de 1-2 cm de diâmetro, bem delimitados, sólidos e com aspecto inflamado, indolores, nas regiões dorsal e interdigital; o animal também apresentava onicogrifose em todos os membros. As mucosas oral e ocular estavam normocoradas e os parâmetros vitais estavam normais para a espécie.

Diante do quadro clínico, suspeitou-se de dermatofitose por leishmaniose visceral cutânea tendo sido, nesse momento, solicitado hemograma completo, dosagem de alanina aminotransferase (ALT), aspartato aminotransferase (AST), fosfatase alcalina (FA), ureia, creatinina e creatina kinase (CK), exame parasitológico de pele e citologia de medula óssea (região esternal) e linfonodos poplíteos e cervical superficial direito e esquerdo, para pesquisa de formas de Leishmania spp. No primeiro momento não foi aconselhado realizar a citologia dos nódulos, pois estavam com sinais de inflamação que acabariam interferindo no resultado, então optou-se por tratar a inflamação e, no retorno do animal, realizar a citologia.

O exame parasitológico direto de raspado da pele foi negativo para a presença de fungos e ácaros. Os achados hematológicos revelaram anemia normocítica normocrômica e a avaliação bioquímica revelou discreto aumento da ureia. As avaliações citológicas de linfonodos e medula óssea foram negativas para a presença de formas amastigotas de Leishmania spp. Com base nos achados, foi prescrita terapia domiciliar à base de cefalexina $(20 \mathrm{mg} / \mathrm{kg} / \mathrm{BID} / 15$ dias), banhos com shampoo de clorexidina + cetoconazol (a cada 3 dias/30 dias) e limpeza dos nódulos, com aplicação de merthiolate spray (BID/15 dias), solicitando-se o retorno do paciente após 15 dias.

Ao retorno, constatou-se que os nódulos já apresentavam melhora do quadro inflamatório, mas as lesões dermatológicas continuavam com as mesmas características. Diante disso, solicitou-se a colheita de biopsia aspirativa, no qual o exsudato dos nódulos foi encaminhado para o teste de reação em cadeia pela polimerase (PCR) e a citologia da biopsia aspirativa, para avaliação parasitológica.

Os exames parasitológicos confirmaram o diagnóstico de leishmaniose pela visualização de formas amastigotas nos esfregaços confeccionados a partir das amostras do exsudato presente no nódulo. O resultado da PCR também foi positivo para Leishmania spp. nas amostras de fragmentos dos nódulos cutâneos, mas a identificação da espécie de Leishmania não pode ser realizada.

Na sequência, após toda a orientação dada ao tutor, este decidiu procurar o tratamento para o animal em outra clínica veterinária, pois o mesmo não era, à época, realizado na clínica em que houve 0 atendimento do paciente.

\section{Discussão}

No presente relato, o paciente canino apresentava um padrão de lesão dermatológica nodular, com presença de nódulos de diferentes tamanhos e em distintas regiões, e esse padrão dermatológico é relatado em casos de leishmaniose visceral canina. Nesse paciente também foi possível identificar onicogrifose que é um sinal clínico bastante comum na leishmaniose visceral (ANDRADE, 2012). 
As alterações dermatológicas crônicas presentes no paciente em questão poderiam estar associadas à outras enfermidades como hipotireoidismo e demodiciose (sarna demodécica). No entanto, constatou-se que estavam relacionadas à leishmaniose. A dermatite esfoliativa é a manifestação clínica cutânea mais comum na LVC, podendo estar acompanhada de descamação, hipotricose e alopecia (AZEVEDO et al., 2008; DIAS et al., 2011). Neste relato, este padrão dermatológico alopécico-descamativo também se encontrava presente, porém, de modo discreto, havendo predomínio do padrão nodular.

Mesmo que a análise do material oriundo de linfonodos e medula óssea tenha sido negativa para a presença de parasitas, pode-se constatar que o exame citológico e do material proveniente do nódulo foram importantes e conclusivos para o diagnóstico de leishmaniose (KRAUSPENHAR et al., 2007).

\section{Considerações finais}

Conclui-se que a citologia dos nódulos dérmicos foi um método complementar de diagnóstico de leishmaniose em um cão negativo ao exame parasitológico direto realizado em amostras de medula óssea e de linfonodos.

Destaca-se a importância de se submeter cães à avaliação citológica de nódulos, quando estes apresentarem sinais clínicos dermatológicos, particularmente em áreas endêmicas para a leishmaniose visceral canina.

\section{Referências}

ANDRADE, M. M. C. Células CD4+ FOXP3+ produzem IL-10 no baço de cães com leishmaniose visceral. 2012. 54 f. Dissertação (Mestrado em Ciência Animal) - Faculdade de Medicina Veterinária, Universidade Estadual Paulista "Júlio de Mesquita Filho", Araçatuba, 2012.

AZEVEDO, E. M. R. et al. Leishmaniose visceral canina em cão de Caldas Novas, Goiás. Revista Brasileira de Parasitologia Veterinária, v. 17, supl. 1, p. 339- 341, 2008.

DIAS, E. L. et al. Canine Visceral Leishmaniasis (CVL): seroprevalence, clinical, hematological and biochemical findings of dogs naturally infected in an endemic area of São José de Ribamar municipality, Maranhão State, Brazil. Ciência Animal Brasileira, v. 9, n. 3, p. 740-745, 2011.

KRAUSPENHAR, C. et al. Leishmaniose visceral em um canino de Cruz Alta, Rio Grande do Sul, Brasil. Ciência Rural, v. 37, n. 3, p. 907-910, 2007. DOl: https://doi.org/10.1590/S0103-84782007000300052.

LAURENTI, M. D. et al. Asymptomatic dogs are highly competent to transmit Leishmania (Leishmania) infantum chagasi to the natural vector. Veterinary Parasitology, Amsterdam, v. 196, n. 3/4, p. 296 300, 2013. DOI: https://doi.org/10.1016/j.vetpar.2013.03.017.

SOLANO-GALLEGO, L. et al. LeishVet guidelines for the practical management of canine leishmaniosis. Parasites \& Vectors, Londres, v. 4, n. 86, p. 1-16, 2011. DOI: https://doi.org/10.1186/1756-3305-4-86. 